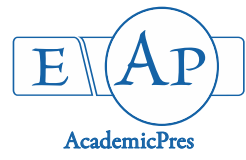

\title{
Assessment of Aglycones Isoflavone Profiling of Staple Indian Grain Flours and Soybean Sprout-Flour
}

\author{
Raman MANOHARLAL*, Saiprasad V.S. GANDRA \\ ITC Life Science and Technology Centre (LSTC), Peenya Industrial Area, 1st Phase, Bengaluru-560058, Karnataka, \\ India; ramanpdfo1@gmail.com (*correspondingauthor); saiprasad.gandra@itc.in
}

\begin{abstract}
In the present study, investigation of fourteen traditional and most commonly used Indian staple grain flour types (viz. wheat, white rice, processed little millet, maize, all-purpose/refined wheat flour, chickpea flour, toasted gram flour, little millet, quinoa, soybean, white millet, pearl millet, semolina/cream of wheat and finger millet) was undertaken for the assessment of 3 major bioactive aglycone forms of isoflavone (IF): daidzein (DI), glycitein (GY) and genistein (GN), with a special interest on the effect of sprouting on total and individual IF components. The obtained results showed that the content and composition of total IF were negligible among all the investigated flours except for soybean, wherein detectable total $\left(227 \mathrm{mg} \mathrm{kg}^{-1}\right)$ and individual IF (45, 129 and $53 \mathrm{mg} \mathrm{kg}^{-1}$ for DI, GY and GN respectively) components were observed. From soybean mature seeds to sprouts formation with $\sim 80 \%$ germination rate at a pilot-scale, a $31 \%$ increase in total IF $\left(298 \mathrm{mg} \mathrm{kg}^{-1}\right)$, characterised by an individual and respective increment of $30 \%\left(58 \mathrm{mg} \mathrm{kg}^{-1}\right), 25 \%\left(161 \mathrm{mg} \mathrm{kg}^{-1}\right)$ and $48 \%\left(78 \mathrm{mg} \mathrm{kg}^{-1}\right)$ in corresponding DI, GY and GN components, was observed. The current results demonstrated that for the Indian scenario, contribution of aforementioned grains, other than soybean in daily dietary intake of IF is negligible and sprouting represents an effective way to enhance the endogenous IF content.
\end{abstract}

Keywords: daidzein; flours; genistein; glycitein; HPLC; isoflavones

Abbreviations: DI - Daidzein; GN - Genistein; GY - Glycitein; HPLC - High-Performance Liquid Chromatography; IF Isoflavones

\section{Introduction}

Isoflavones (IF), non-steroidal estrogen mimics, termed as 'phytoestrogen', constituting a sub-class of natural bioflavonoids, are a large group of plant secondary metabolites (Cos et al., 2003; Hwang et al., 2006). Over the past few decades, IF have attracted considerable worldwide attention mainly due to their enormous health benefits (Crozier et al., 2009; Garcia-Lafuente et al., 2009; Terashima et al., 2012). IF are known to possess antioxidant, anti-microbial, anti-allergic, ant-inflammatory, anti-viral, anti-carcinogenic, anti-neoplastic, antihelminthic, anti-thrombotic and anti-hormonal properties (Mira et al., 2002). A diverse array of epidemiological and associated meta-analyses strongly supports the notion that persistent consumption of IF enriched products imparts natural remedies by offering protection against cancers (prostate and breast), diabetes, obesity, osteoporosis, hypercholesterolemia, cardiovascular and neuro-degenerative disorders, as well as relieving from menopausal symptoms (Kalaiselvan et al., 2010).
In plants, major and parental IF are daidzein (DI), glycitein (GY) and genistein (GN), present both in free(aglycones) and conjugated-forms [glycosides: glucosides ( $\beta$ glycosides), acetyl-glucosides ester ( $6^{\prime}$-o-acetylglycosides) and malonyl-glucosides ester (6'-o-malonylglycosides)], with the latter being the predominant form (Friedman and Brandon, 2001; Ho et al., 2002). After consumption, the conjugated-glycosides are hydrolysed in the human gut to their respective parental aglycones, which are further metabolised and excreted (Kulling et al., 2002). Thereby, the aforementioned health benefits by IF relates exclusively to their bioactive aglycone components, DI, GY and GN. However, in most clinical trials, a little attention has been paid towards exact aglycone profiling, wherein the declared food content is commonly expressed in terms of total IF without any specification related to their form (free/conjugated) and proportion. Hence, it becomes mandatory to determine their bioactive aglycones either by acid- (Müllner and Sontag, 2000) or enzymatic-hydrolysis (Franke et al., 1994), in order to know and estimate the precise levels of bioactive IF exposure to their consumers. 
486

There are published data on IF levels of vegetables, fruits, nuts, cereals, oilseeds, legumes, berries and beverages such as tea, coffee and wine (Mazur, 1998; Mazur et al., 1998; Liggins et al., 2000; Liggins et al., 2002). Recently, USDA also released the database on IF content from 560 food items (Bhagwat et al., 2008). Paradoxically, most of these studies has analysed the IF composition from the foods and food-products available in the USA and Western countries. However, there was no systematic report of such a kind in Indian context, wherein diverse array of dietary grain food-products are consumed on a daily basis. Thereby, the following research was conducted to investigate the composition of bioactive aglycones DI, GY and GN in staple Indian grain flours, with a special interest to identify the effect of sprouting on total and individual IF aglycone components. A comparative insight of aglycone IF forms of 14 commonly used Indian grain flours along with a positive effect of sprouting on IF contents are reported here within.

\section{Materials and Methods}

\section{Seed materials and flourpreparation}

A diverse array of staple Indian grain flours were used in the study (Table 1). For this, commercially available grain seeds / flours [viz. wheat (Triticum aestivum), white rice (Oryza sativa), processed little millet, maize (Zea mays), allpurpose/refined wheat flour, chickpea flour (Cicer arietinum), toasted gram flour, little millet (Panicum sumatrense), quinoa (Chenopodium quinoa), soybean (Glycine max), white millet (Sorghum vulgare), pearl millet (Pennisetum glaucum), semolina/cream of wheat and finger millet (Eleusine coracana)] were purchased from the local retail stores of Bengaluru, India. A comprehensive overview of aforementioned flours was described earlier (Duyff, 2012). For making seed-flour, the dried seeds (moisture content $<7 \%$ ) were cleaned and sorted out thoroughly to make them free from dust, dirt, stubbles and foreign matter. Damaged, immature/broken with cracked hull and smallsized seeds were discarded mechanically so as to obtain clean seeds of uniform size. The cleaned seeds were milled to a fine powder using analytical grinder mill (CT 193 Cyclotec $^{\mathrm{TM}}$, FOSS India Pvt. Ltd., Mumbai) and passed through a $0.6 \mathrm{~mm}$ sieve to obtain flour of $500 \mu \mathrm{m}$ particle size. The obtained flours were stored as a fine powder in tightly closed containers at $4^{\circ} \mathrm{C}$ till further use.

\section{Chemicals}

HPLC-grade authentic aglycone isoflavone (IF) standards: Daidzein (D7802), Glycitein (43534), Genistein (G6649), with > 99\% purity and analytical reagent (AR) grade chemicals used in the hereby study were obtained from Sigma-Aldrich (St. Louis, MO, USA).

Soybean sprouting conditions and sprout-flourpreparation

Soybean seeds var. 'JS9560' (a widely used commercial variety in Central India), procured from ICAR-Indian Institute of Soybean Research (IISR), Indore, Madhya Pradesh were used in the study. Cleaned and mechanically sorted seeds were surface sterilized with $0.5 \%(\mathrm{w} / \mathrm{v})$ sodium hypochlorite $(\mathrm{NaClO})$ for $5 \mathrm{~min}$ (to avoid fungal invasion) and rinsed thoroughly with running distilled water to remove any traces of $\mathrm{NaClO}$. About $5 \mathrm{~kg}$ of cleaned and surface sterilized seeds per batch were soaked in 251 of potable water for $4 \mathrm{~h}$ with a constant shaking at $10 \mathrm{rpm}$ in a customised motor seed dressing drum (GMW, Ambala, India), followed by draining and rinsing with distilled water. The soaked seeds were subsequently distributed evenly on filter paper in a single layer in sterile germination trays. For each sample, 5 germination trays harbouring $1 \mathrm{~kg}$ seeds/tray were evaluated in three biological replicate. Each germination tray was wrapped with a muslin clothes (to allow entry of oxygen for the germinating seeds, while minimizing the contamination during the test-period) and placed in the customised seed germinator [ACM-78093-S, Acmas technologies Pvt. Ltd., India] at $30{ }^{\circ} \mathrm{C}$ with $100 \%$ relative humidity for 3 days in the absence of light (AgraharMurugkar and Jha, 2009). Germination trays were watered daily according to its requirement with distilled water during the course of germination. Physiological germination in terms of visible radical protrusion of at least $2 \mathrm{~mm}$ (ISTA, 1999) was assessed each day over a test period of 3 days, wherein no further radicle emergence was noted. Sprouts obtained after $3^{\text {rd }}$ day of germination were subjected to drying in an hot air oven incubator (Inlab equipment; 230 volt, $5.4 \mathrm{~A}$ ) at $50-55^{\circ} \mathrm{C}$ to a final moisture content of $6-8 \%$, a level recommended for the production of soy-flour (Gandhi, 2008). Dried sprouts were milled to a fine powder using analytical grinder mill, passed through a $0.6 \mathrm{~mm}$ sieve to obtain flour of $500 \mu \mathrm{m}$ particle size. The obtained sproutflour was stored as a fine powder in tightly closed containers at $4^{\circ} \mathrm{C}$ till further use.

\section{IF extraction and estimation}

An HPLC based method for extraction and quantitative estimation of aglycone IF has been adopted (Kumar et al., 2009), with certain modifications. This method relies mainly on acid hydrolysis of 12 endogenous IF isomers to their respective aglycone forms, DI, GY and GN. Sample preparation. Approximately $250 \mathrm{mg}$ of sample was extracted with $5 \mathrm{~cm}^{3}$ of $80 \%$ ethanol followed by acid hydrolysis with $1 \mathrm{~cm}^{3}$ of conc. $\mathrm{HCl}$ for $2 \mathrm{~h}$ in a boiling water bath. HPLC conditions and instrumentation. An HPLC system equipped with an auto-sampler, a gradient programmer, a solvent pump and a diode array detector (Agilent 1200) was used. The supernatant obtained after centrifugation $(10,000 \mathrm{rpm}$ for $10 \mathrm{~min})$ was passed through a syringe filter $(0.45 \mu \mathrm{m}$, PVDF, $33 \mathrm{~mm})$. Aliquots $\left(20 \mathrm{~mm}^{3}\right)$ of syringe filtered samples were injected into HPLC system housing a C-18 silica column (Inertsil ODS $3 \mathrm{~V} ; 5 \mu \mathrm{m}$ with dimension of $250 \times 4.6 \mathrm{~mm})$. The column oven was maintained at $40{ }^{\circ} \mathrm{C}$. The separation and elution of IF was accomplished by employing a binary gradient mode with solvent A (10\% $\mathrm{ACN})$ and solvent $\mathrm{B}(38 \% \mathrm{ACN})$ at a flow rate of $0.8 \mathrm{~cm}^{3}$ $\mathrm{min}^{-1}$ for $25 \mathrm{~min}$. The solvent system was run as follows (\% solvent A/B), $0 \mathrm{~min}(0 / 100), 5 \mathrm{~min}$ (10/90), $20 \mathrm{~min}$ $(0 / 100)$ and $25 \mathrm{~min}(0 / 100)$. The resolution of DI and of GY and GN was detected at 250 and $260 \mathrm{~nm}$, respectively. Authentic commercially available aglycone IF standards; DI (in methanol), GY (in dimethylformamide) and GN (in methanol) were dissolved at $1 \mathrm{mg} \mathrm{cm}^{-3}\left(1,000 \mathrm{mg} \mathrm{dm}^{-3}\right)$ and subjected to HPLC in a concentration range of $0-10 \mathrm{mg}$ 
$\mathrm{dm}^{-3}$. The resulting peak area was plotted against standard concentration for the linear calibration curve. The retention time of individual standard was used to identify the corresponding peaks from the HPLC chromatograms for each sample. The relative concentration of individual IF was calculated after superimposing the sample chromatogram on their corresponding standard curve. Concentration of DI, GY and GN were summed to compute total IF. Individual and total IF concentraion was expressed as $\mathrm{mg} \mathrm{kg}$ ${ }^{1}$ on a dry weight $(\mathrm{dw})$ basis.

\section{Data analysis}

The results were expressed as means \pm SDs. One-way analysis of variance (ANOVA) was used to analyze the level of statistical significance $(P \leq 0.05)$ between groups.

\section{Results and Discussion}

\section{Evaluation of aglycones IF}

Chromatographic methods allow the quantitation of individual IF aglycone forms DI, GY and GN (Fig. 1), in a complex mixture. Thereby, the selected grain flours used in the hereby study were subjected to acid hydrolysis, followed by HPLC for the separation and quantification of total and individual IF aglycone components. Representative HPLC chromatograms, retention time (RT, in min) and linear equations obtained from the calibration curve of each commercial available authentic IF standards are shown in Fig. 2A. The present HPLC procedure is able to clearly resolve three standard peaks (between 8-15 $\mathrm{min}$ as minimum and maximum RT) corresponding to DI, GY and GN, as an individual IF components. In each case, a linear relationship between IF concentration $(0-10 \mathrm{mg} \mathrm{dm}$ $\left.{ }^{3}\right)$ and the observed peak area was obtained, with a determination coefficient $>99 \%$ (Fig. 2B). The IF profiling depicting the individual aglycone component for each flour are shown in Fig. 3.

Each IF component was identified by comparing its relative RT and DAD spectra with those of the corresponding aglycone standard. Sample peak area corresponding to each of identified aglycone IF were quantified using external standard procedure. The authenticity of method was also monitored by a recovery test, wherein the appropriate concentration of the aglycone recovery standard was added to the sample prior to acid hydrolysis (data not shown). Table 2 summarizes the amount of total and individual aglycone IF components for each flour sample. Notably, total IF content was determined as the sum of individual aglycone IF obtained from each flour. The results demonstrated that except for soybean, no detectable IF was observed from any grain flours examined. In soybean seed-flour, the total IF observed was $227 \mathrm{mg} \mathrm{kg}^{-1}$, wherein aglycones DI, GY and GN accounts for 45, 129 and $53 \mathrm{mg} \mathrm{kg}^{-1}$, respectively. In this regard, Indian daily intake of IF from the grains examined other than soybean could be neglected, while evaluating phytoestrogen intake in tested Indian grains flours. Notably, the observed soybean IF aglycones value and pattern are in well agreement with the previous studies, wherein soybean has been reported to be a rich source of IF with relative high percentage of DI and GN (Vacek et al., 2008). The prevalence of soybean and soy-products in Asian diet with mean IF consumption of 11-47 mg day ${ }^{-1}$ (Arai et al., 2000; Ho et al., 2000; Yamamoto et al., 2001), is in contrast to $1-2 \mathrm{mg} \mathrm{day}^{-1}$ in Western countries (de Strom et al., 1999; Kleijn et al., 2001), thus explain the reason of low incidence of menopausal symptoms (hot flushes) (Nagata et al., 2001) and clinical prostate cancer (Duncan et al., 2003) in Asian countries.

Table 1. List of commonly used staple Indian grain flour types

\begin{tabular}{|c|c|c|}
\hline Common / Local name & English / Scientific name & Food-products \\
\hline Gehun & Whole wheat flour (Triticum aestivum) & Roti/Chappati/Phulka, Parathas, Poori and Tortillas \\
\hline Chawal & White rice (Oryza sativa) & Kozhakatai, Pooris, Rice bhakri/Rotis, Khichdi, Pulav/Biryani and Kheer \\
\hline Kutki rice (Saamai/Sama) & Processed little millet & Bread, Roti, Dosa and Rice (substitute of staple rice) \\
\hline Makai/Makki & Maize (Zea mays) & Makki ki roti, Pudding, Thickener for soups, Stews and Sauces \\
\hline Maida & All-purpose/refined wheat flour & Naan, Bhatura, Luchi, Kulcha, Bread, Biscuits, Muffins and Cakes \\
\hline Besan & $\begin{array}{l}\text { Gram/Garbanzo bean/Chickpea } \\
\text { (Cicer arietinum) }\end{array}$ & $\begin{array}{l}\text { Pakoras/Fritters, Besan ladoos, Khandvi, Dhokla, Methi muthia, Missi roti and Besan } \\
\text { halwa }\end{array}$ \\
\hline Sattu & Toasted gram flour & Sattu drink, Roti/Chappati/Phulka, Parathas, Poori, Laddu and Chilla \\
\hline Kutki/Shavan & Little millet (Panicum sumatrense) & Bread, Roti, Dosa and Rice (substitute of staple rice) \\
\hline Quinoa & Quinoa (Chenopodium quinoa) & $\begin{array}{l}\text { Pseudo-cereal; Food supplement in flour industry in Bread, Biscuits, Dumplings, } \\
\text { Sauces, Noodles, Desserts, Sweets, Flans, Cakes, Yoghurt and Soups }\end{array}$ \\
\hline Soybean/Miracle bean & Glycine max & Food supplement with whole wheat flour in Rotis, Parathas and Pancakes \\
\hline Jowar & White millet (Sorghum vulgare) & Bhakris, Thepla, Thalipeeth and Flat bread \\
\hline Bajra & Pearl millet (Pennisetum glaucum) & $\begin{array}{l}\text { Bajra roti/Bajra bhakri, Thepla, Upma, Dosa, Idli, Vada, Bajjis/Pakoras, } \\
\text { Murrukus/Chakkli, Nipatlu, Pongal, Mudda/Dumpling, Khichdi, Pulav/Biriyani, } \\
\text { Kheer/Payasam, baked products such as Flat bread and Biscuits or cooked just like } \\
\text { boiled rice }\end{array}$ \\
\hline Sooji/Rava/Rawa & Semolina/Cream of wheat & Savory, Sooji halwa, Rava dosa, Rava kesari and Rava upma \\
\hline Ragi/Nachni/Mandua & Finger millet (Eleusine coracana) & $\begin{array}{c}\text { Ragi dosa, Idli, Drinks, Puddlings, Dumplings, Roti, Upma, Porridge, Mudde and } \\
\text { Payasam }\end{array}$ \\
\hline
\end{tabular}


Table 2. Detection and quantification of total and individual aglycone IF contents from staple Indian grain flours

\begin{tabular}{|c|c|c|c|c|}
\hline Sample & DI & $\overline{G Y}$ & GN & Total IF \\
\hline Wheat & n.d. & n.d. & n.d. & n.d. \\
\hline White rice & n.d. & n.d. & n.d. & n.d. \\
\hline Processed little millet & n.d. & n.d. & n.d. & n.d. \\
\hline Maize & n.d. & n.d. & n.d. & n.d. \\
\hline All-purpose/refined wheat flour & n.d. & n.d. & n.d. & n.d. \\
\hline Chickpea flour & n.d. & n.d. & n.d. & n.d. \\
\hline Toasted gram flour & n.d. & n.d. & n.d. & n.d. \\
\hline Little Millet & n.d. & n.d. & n.d. & n.d. \\
\hline Quinoa & n.d. & n.d. & n.d. & n.d. \\
\hline Soybean & $44.77 \pm 5.91$ & $129.44 \pm 9.24$ & $53.13 \pm 4.98$ & $227.34 \pm 18.54$ \\
\hline White millet & n.d. & n.d. & n.d. & n.d. \\
\hline Pearl millet & n.d. & n.d. & n.d. & n.d. \\
\hline Semolina/Cream of wheat & n.d. & n.d. & n.d. & n.d. \\
\hline Finger millet & n.d. & n.d. & n.d. & n.d. \\
\hline
\end{tabular}

"Total isoflavones (IF) were represented as the sum of daidzein (DI), glycitein (GY) and genistein (GN).

Values $\left(\mathrm{mg} \mathrm{kg}^{-1}\right)$ given are means \pm SDs from three independent experiments $(n=3)$.

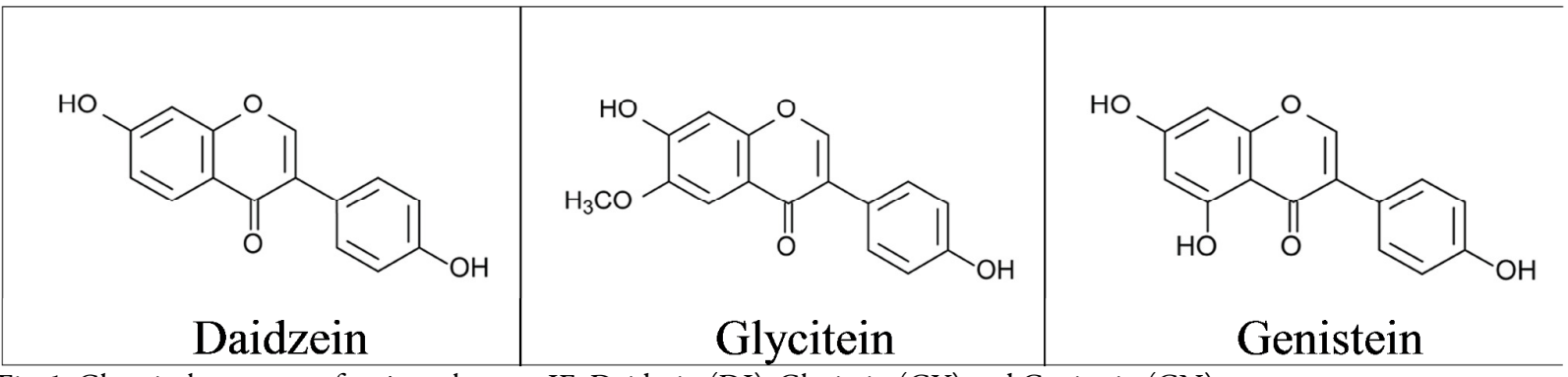

Fig. 1. Chemical structure of major aglycones IF; Daidzein (DI), Glycitein (GY) and Genistein (GN)

A

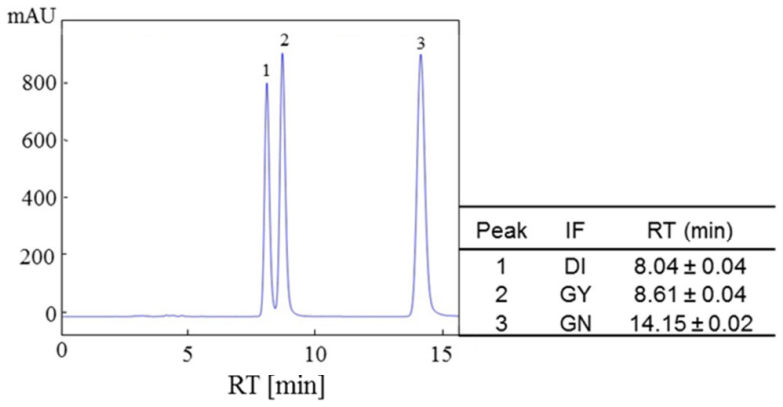

B

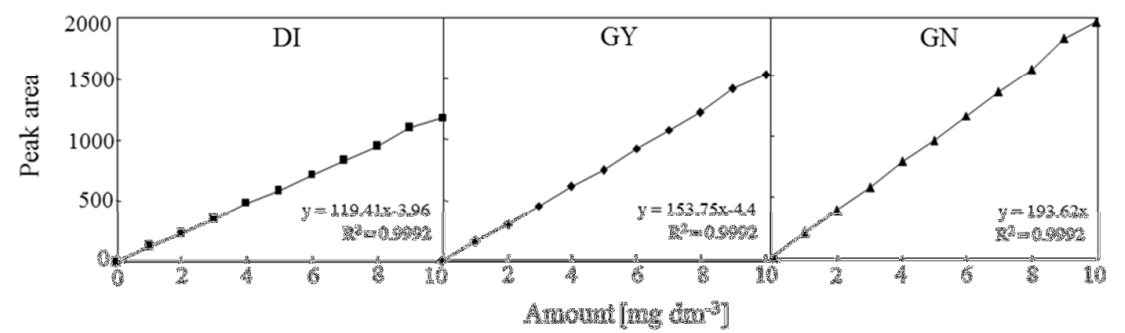

Fig. 2. A typical chromatographic separation of aglycone IF standards; A. Representative HPLC chromatogram illustrating separation of aglycone IF standards; daidzein (DI), glycitein (GY) and genistein (GN). Each IF standard was evaluated by their peak area with corresponding retention time $(\mathrm{min})$; B. Different concentration of each aglycone standard $\left(0-10 \mathrm{mg} \mathrm{dm}^{-3}\right)$ was evaluated. Standard calibration graphs displaying the linearity between chromatogram peak area and amount of each aglycone IF standard. The R2 values for the fitted lines displaying $>0.99$ indicates a good fit and gives confidence for reliable IF estimation 

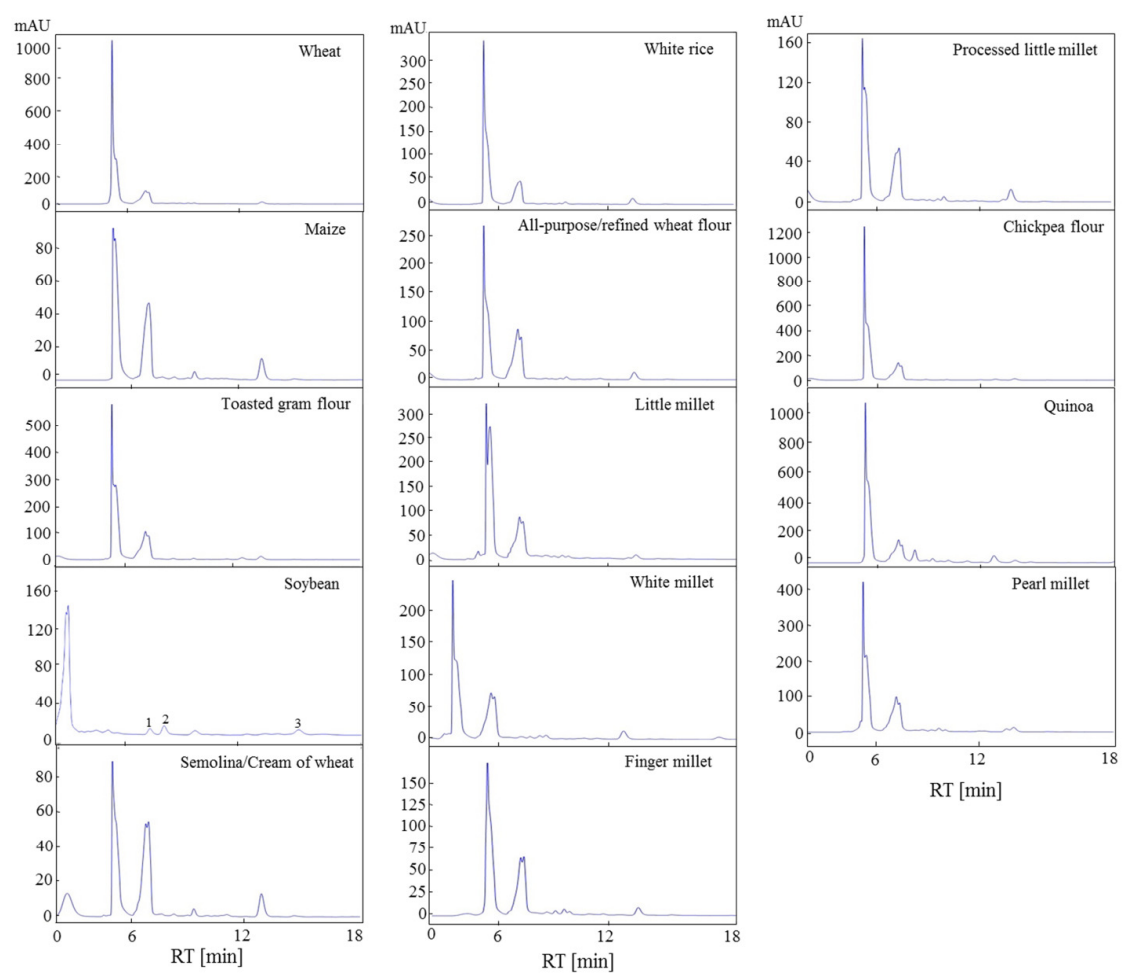

Fig. 3. A typical chromatographic separation of IF extracts from investigated Indian grain flours; Representative HPLC chromatograms showing the separation of ethanol soluble and acid hydrolysable IF extracts from various Indian grain flours. The individual aglycone from each sample was evaluated by peak identification with overlapping retention time (min) of corresponding aglycone standard

Effect of sprouting on IF levels

Being the richest source of IF, soybean represents an ideal model system for improvement of endogenous IF in other unexplored grain flours. Germination represent a cost effective way of enhancing endogenous IF levels of legumes (Chiarello et al., 2006; Gao et al., 2015). Nevertheless aside from circumstantial evidence reported only under laboratory conditions, a practical exploitation of germination process is very scarce. For a commercial perspective, it was hereby evaluated the effect of soybean sprouting on IF content at a pilot-scale. Soybean seeds of commercial variety 'JS9560' were sprouted under controlled environmental conditions at a pilot-scale, with a germination rate of $\sim 80 \%$ (Fig. $4 \mathrm{~A}$ ). High quality driedflours was made from sprouts after 3 days of germination (Fig. 4B inset), as per recommendation for the production of soy-flour (Gandhi, 2008). HPLC chromatograms depicting the separation of individual IF components from soybean mature seed- and sprout-flours are shown in Fig. $4 \mathrm{~B}$. The IF contents of soybean sprout-flours significantly increased compared to the corresponding soybean seed counterpart during the assay-period. Table 3 depicts the variation of total and individual IF components in soybean mature seed-and sprout-flours.

The present findings showed that soybean sprouting at pilot-scale resulted in an increment of $31 \%$ in total IF (from 227 to $298 \mathrm{mg} \mathrm{kg}^{-1}$ ). Within IF, an individual and respective increment of $30 \%$ (from 45 to $58 \mathrm{mg} \mathrm{kg}^{-1}$ ), $25 \%$ (from 129 to $161 \mathrm{mg} \mathrm{kg}^{-1}$ ) and $48 \%$ (from 53 to $78 \mathrm{mg} \mathrm{kg}^{-1}$ ) in corresponding DI, GY and GN content was observed. The variable trends of DI, GY and GN observed during sprouting could be due to their specific role during the different growth stages of soybean.

Notably, among the three aglycones, the best described ones are DI and GI, which show anti-disease properties (Choi and Kim, 2013; He et al., 2015; Kaur and Badhan, 2015). The observed increment in DI and GI in soybean sprouts could be related to activation of endogenous $\beta$ glucosidase activity (EC3.2.1.21) either during soaking or germination (Chiarello et al., 2006), resulting in a potent hydrolysis of their substrates, $\beta$-glycoside IF to their aglycone forms.

Germination is a complex metabolic process leading to radical changes in primary- and secondary-metabolism, resulting in the production of various biologically active compounds (such as lecithin, phytosterols, saponins, estrogenic, phenolic and antioxidant compounds etc.), which could be used directly or indirectly for plant growth and survival (Bau et al., 2000; Kuo et al., 2004). Regarding this, a recent comparative study between high- and low-IF soybean cultivars also revealed the differential expression of IF synthesising phenylpropanoid pathway genes phenylalanine ammonia lyase $(P A L)$, chalcone synthase $(C H S)$, chalcone isomerase $(C H I)$, chalcone reductase $(C H R)$ and isoflavone synthase (IFS), which accounted for the observed differences in their endogenous IF concentrations (Chen et al., 2011). In this context, it is pertinent to mention here that apart from enhancing the 
490

endogenous IF levels, soybean sprouting have been also reported to significantly improve its nutritional, physicochemical and biological properties (Bau et al., 1997; Bau et al., 2000; Dikshit and Ghadle, 2003; Agrahar-Murugkar and Jha, 2009). Thus, germination at an industrial-scale could provide an exciting prospect of meeting up the food- market expectation, with a considerable high IF levels, along with complementary high nutritional values.

Furthermore the selection of the suitable food grains coupled with a germination process could provide a good source of germinated product(s) harbouring enriched bioactive IF for nutritional and health benefits.

Table 3. Detection and quantification of total and individual aglycone IF contents from soybean mature seed-and sprout-flours

\begin{tabular}{ccccc}
\hline Sample & DI & GY & GN & ${ }^{*}$ Total IF \\
\hline Soybean seeds & $44.77 \pm 5.91$ & $129.44 \pm 9.24$ & $53.13 \pm 4.98$ & $78.46 \pm 6.64$ \\
Soybean sprouts & $58.37 \pm 5.19$ & $161.5 \pm 10.54$ & $298 \pm 18.54$ \\
\hline
\end{tabular}

"Total isoflavones (IF) were represented as the sum of daidzein (DI), glycitein (GY) and genistein (GN).

Values $\left(\mathrm{mg} \mathrm{kg}^{-1}\right)$ given are means \pm SDs from three independent experiments $(n=3)$.

Asterisks indicate significant differences $(\mathrm{P} \leq 0.05)$ when compared with the control

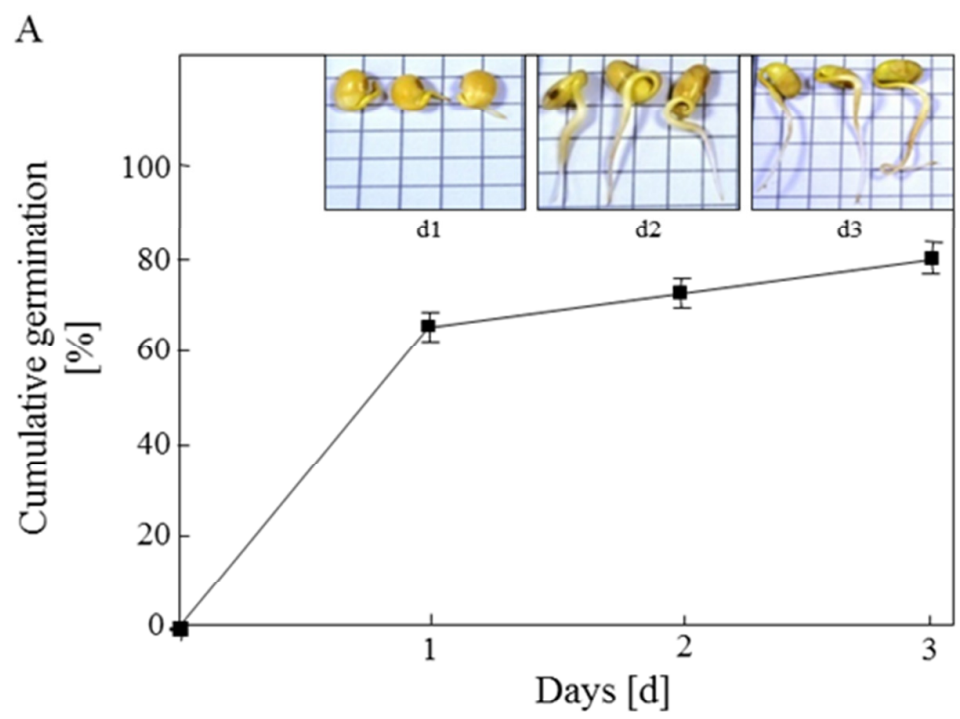

B

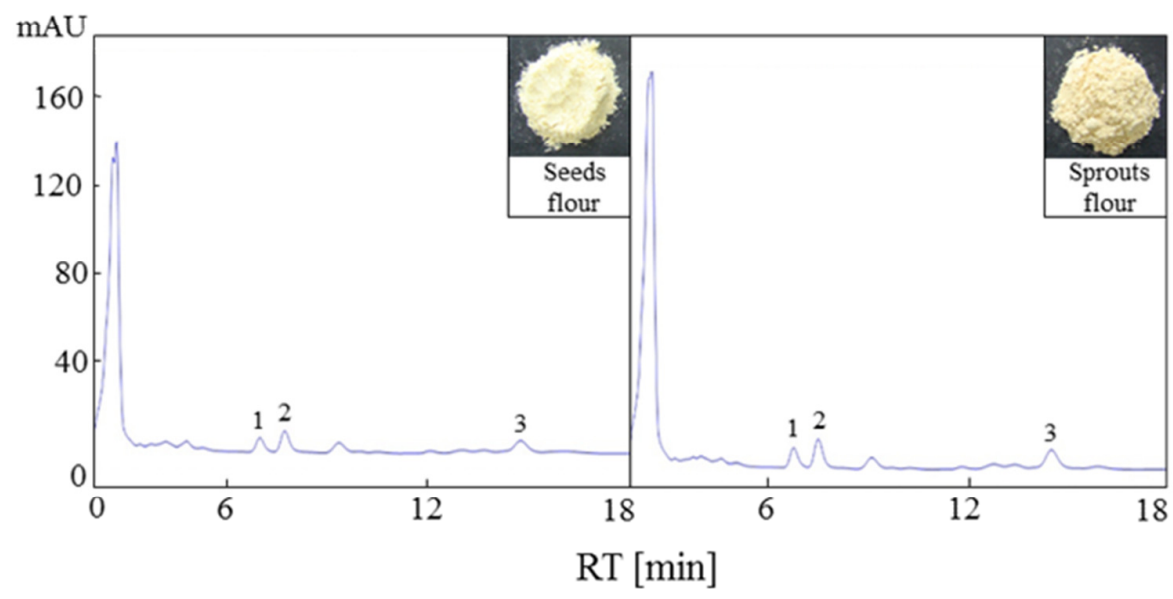

Fig. 4. Effect of sprouting on total and individual aglycone IF components of soybean; A. Cumulative germination (\%) was measured over a test-period of $3 \mathrm{~d}$ following $4 \mathrm{~h}$ of priming in water. Means \pm SDs, $n=3$, with 50 seeds per measurements. Inset depicts the representative images of temporal sprouts formation during the assay-period; B. Representative HPLC chromatograms showing the separation of ethanol soluble and acid-hydrolysable IF extracts from mature seed-(left-panel) and sprout-flours (right-panel) at 3 days of germination. The individual aglycone from each sample was evaluated by peak identification with overlapping retention time $(\mathrm{min})$ of corresponding aglycone standard. Inset shows the soybean flours prepared from the seeds and sprouts at 3 days of germination 


\section{Conclusions}

The present study suggests that an improvement in the endogenous levels of IF by sprouting at an industrial-scale would aid in the development of value-added, nutritional and harmless feed- and food-product, which will ensure better nutritional security. The results from the present investigation could also be extended to other unexplored grains, thereby a complete inventory of aglycones IF can be generated, which will further enhance our understanding of IF biosynthesis. A promising method for the industrial-scale production of IF-enriched flours and/ foods with enhanced nutritional benefits, as well as purification of IF for use as a phytoestrogen in 'functional-foods' can be designed thereof. Our future studies are directed to achieve these goals.

\section{Acknowledgements}

The hereby research received no specific grant from any funding agency in the public, commercial or not-for-profit sectors. The authors would like to acknowledge Dr. C.C. Lakshmanan [Head, Corporate R\&D, ITC Limited, ITC Life Science and Technology Centre (LSTC)] for his consistent support. Appreciation is extended to Mr. K. Madhavakrishna (ITC- LSTC) for his valuable initiative on HPLC experiments.

\section{References}

Agrahar-Murugkar D, Jha K (2009). Effect of sprouting on nutritional and functional characteristics of soybean (Glycine max L). Journal of Food Science and Technology 46(3):240-243.

Arai Y, Watanabe S, Kimira M, Shimoi K, Mochizuki R, Kinae N (2000). Dietary intakes of flavonols, flavones and isoflavones by Japanese women and the inverse correlation between quercetin intake and plasma LDL cholesterol concentration. The Journal of Nutrition 130(9):2243-2250.

Bau H, Villaume C, Nicolas J, Méjean L (1997). Effect of germination on chemical composition, biochemical constituents and antinutritional factors of soya bean (Glycine max) seeds. Journal of the Science of Food and Agriculture 73(1):1-9.

Bau HM, Villaume C, Méjean L (2000). Effects of soybean (Glycine max) germination on biologically active components, nutritional values of seeds, and biological characteristics in rats. Food / Nahrung 44(1):2-6.

Bhagwat S, Haytowitz DB, Holden JM (2008). USDA database for the isoflavone content of selected foods. Release 2.0. Maryland: US Department of Agriculture pp 15.

Chen H, Seguin P, Jabaji S, Liu W (2011). Spatial distribution of isoflavones and isoflavone-related gene expression in high-and low-isollavone soybean cultivars. Canadian Journal of Plant Science 91(4):697-705.

Chiarello MD, Le Guerroué J-l, Chagas CMSFranco OL, Bianchini E, Joao MJ (2006). Influence of heat treatment and grain germination on the isoflavone profile of soy milk. Journal of Food Biochemistry 30(2):234 247.

Cos P, De Bruyne T, Apers S, Berghe DV, Pieters L, Vlietinck AJ (2003). Phytoestrogens: recent developments. Planta Medica 69(7):589-599.

Crozier A, Jaganath IB, Clifford MN (2009). Dietary phenolics: chemistry, bioavailability and effects on health. Natural Product Reports 26(8):1001-1043.

de Kleijn MJ, van der Schouw, Yvonne T, Wilson PW, Adlercreutz H, Mazur W, Grobbee DE, Jacques PF (2001). Intake of dietary phytoestrogens is low in postmenopausal women in the United States: The Framingham study. The Journal of Nutrition 131(6):1826-1832.

Dikshit M, Ghadle M (2003). Effect of sprouting on nutrients, antinutrients and in vitro digestibility of the MACS-13 soybean variety. Plant Foods for Human Nutrition 58(3):1-11.

Duncan AM, Phipps WR, Kurzer MS (2003). Phyto-oestrogens: best practice and research. The Journal of Clinical Endocrinology \& Metabolism 17(2):253-271.

Duyff RL (2012). Flour power: Learn about different kinds of flours. Retrievd 27 Febr 2018 from https://foodandnutrition.org/summer2012/flour-power-learn-different-kinds-llours/

Franke AA, Custer LJ, Cerna CM, Narala KK (1994). Quantitation of phytoestrogens in legumes by HPLC. Journal of Agricultural and Food Chemistry 42(9):1905-1913.

Friedman M, Brandon DL (2001). Nutritional and health benefits of soy proteins. Journal of Agricultural and Food Chemistry 49(3):1069-1086.

Gandhi A (2008). Development of HACCP procedure for the production offull fat soy flour. International Food Research Journal 15(2):141-154.

Gao Y,Yao Y,Zhu Y, Ren G(2015).Isoflavone content and composition in chickpea (Cicer arietinum L.) sprouts germinated under different conditions. Journal of Agricultural and Food Chemistry 63(10):27012707.

Garcia-Lafuente A, Guillamón E, Villares A, Rostagno MA, Martínez JA (2009). Flavonoids as anti-inflammatory agents: implications in cancer and cardiovascular disease. Inflammation Research 58(9):537-552.

Guerroué JLL, Chagas CMS, Franco OL, Bianchini E, João MJ (2006). Influence of heat treatment and grain germination on the isoflavone profile of soy milk.Journal of Food Biochemistry30(2):234247.

Ho HM, Chen RY, Leung LK, Chan FL, Huang Y, Chen ZY (2002). Difference in flavonoid and isoflavone profile between soybean and soy leaf.Biomedicine \& Pharmacotherapy 56(6):289-295.

Ho SC, WooJL, Leung SS, Sham AL, Lam T, Janus E (2000). Intake of soy products is associated with better plasma lipid profiles in the Hong Kong Chinese population. The Journal of Nutrition 130(10):2590-2593.

Hwang CS, Kwak HS, Lim HJ, Lee SH, Kang YS, Choe TB, Hur HG, Han KO (2006). Isoflavone metabolites and their in vitro dual functions: they can act as an estrogenic agonist or antagonist depending on the estrogen concentration. The Journal of Steroid Biochemistry and Molecular Biology 101(4-5):246-253.

International Seed Testing Association (ISTA) (1999). International rules for seed testing. Seed Science and Technology 27 (Supplement):1-333.

Kalaiselvan V, Kalaivani M, Vijayakumar A, Sureshkumar K, Venkateskumar K (2010). Current knowledge and future direction of research on soy isoflavones as a therapeutic agents. Pharmacognosy Reviews 4(8):111-117.

Kaur M, Badhan RKS (2015). Phytoestrogens modulate breast cancer resistance protein expression and function at the blood-cerebrospinal fluid barrier. Journal of Pharmacy \& Pharmaceutical Sciences 18(2):132-154. 
492

Kulling SE, Lehmann L, Metzler M (2002). Oxidative metabolism and genotoxic potential of major isoflavone phytoestrogens. Journal of Chromatography B 777(1-2):211-218.

Kumar V, Rani A, Dixit AK, Bhatnagar D, Chauhan G (2009). Relative changes in tocopherols, isoflavones, total phenolic content, and antioxidative activity in soybean seeds at different reproductive stages. Journal of Agricultural and Food Chemistry 57(7):2705-2710.

Kuo Y, Rozan P, Lambein F, Frias J, Vidal-Valverde C (2004). Effects of different germination conditions on the contents of free protein and non-protein amino acids of commercial legumes. Food Chemistry 86(4):537-545.

Liggins J, BluckL, Runswick S, Atkinson C, Coward W, Bingham S (2000). Daidzein and genistein contents of vegetables. British Journal of Nutrition 84(5):717-725.

Liggins J, Mulligan A, Runswick S, Bingham S (2002). Daidzein and genistein content of cereals. European Journal of Clinical Nutrition $56(10): 961$.

Mazur W (1998). Phytoestrogen content in foods. Baillière's Clinical Endocrinology and Metabolism 12(4):729-742.

Mazur WM, Duke JA, Wähälä K, Rasku S, Adlercreutz H (1998). Isoflavonoids and lignans in legumes: Nutritional and health aspects in humans 1. The Journal of Nutritional Biochemistry 9(4):193-200.

Mira L, Tereza Fernandez M, Santos M, Rocha R, Helena Florêncio M, Jennings KR (2002). Interactions of flavonoids with iron and copper ions: a mechanism for their antioxidant activity. Free Radical Research 36(11):1199-1208.

Müllner C, Sontag G (2000). HPLC with coulometric electrode array detection determination of daidzein and genistein in soy based infant food, soy milk and soy based supplements. European Food Research and Technology 211(4):301-304.

Nagata C, Takatsuka N, Kawakami N, Shimizu H (2001). Soy product intake and hot flashes in Japanese women: results from a communitybased prospective study. American Journal of Epidemiology 153(8):790-793.

Strom SS, Yamamura Y, Duphorne CM, Spitz MR, Babaian RJ, Pillow PC, Hursting SD (2000). Phytoestrogen intake and prostate cancer: A casecontrol study usinga new database. Nutrition and Cancer 36(2):243.

Terashima M, Kakuno Y, Kitano N, Matsuoka C, Murase M, Togo N, Watanabe R, Matsumura S (2012). Antioxidant activity of flavonoids evaluated with myoglobin method. Plant Cell Reports 31(2):291-298.

VacekJ, Klejdus B, Lojková L, Kubán V (2008). Current trends in isolation, separation, determination and identification of isoflavones: a review. Journal of Separation Science 31(11):2054-2067.

Yamamoto S, Sobue T, Sasaki S, Kobayashi M, Arai Y, Uehara M, Adlercreutz H, Watanabe S, Takahashi T, Iitoi Y (2001). Validity and reproducibility of a self-administered food-frequency questionnaire to assess isoflavone intake in a Japanese population in comparison with dietary records and blood and urine isoflavones. Journal of Nutrition 131(10):2741-2747. 